\title{
Effect of heart rate on the risk of developing metabolic syndrome
}

\author{
Taku Inoue $^{1}$, Kunitoshi Iseki ${ }^{2}$, Chiho Iseki ${ }^{2}$, Yusuke Ohya ${ }^{3}$, Kozen Kinjo ${ }^{4}$ and Shuichi Takishita ${ }^{3}$
}

High heart rate and metabolic syndrome are risk factors for cardiovascular morbidity and mortality. The relationship between heart rate and risk of developing metabolic syndrome has not been studied in a large cohort. We examined the relationship between heart rate and the risk of developing metabolic syndrome in individuals who participated in a health evaluation program from 1997 to 2002. Among the 7958 individuals who participated in the program, 1677 were excluded from our study because they were being treated for heart disease or had been diagnosed with metabolic syndrome at baseline examination. A total of 6281 individuals (3789 men and 2492 women, 20-89 years of age) were evaluated. They were categorized according to their baseline heart rate and were followed up for a mean of $47 \pm 16$ months (range: 7-71 months). Over the 5-year period, 619 individuals $(9.9 \%)$ developed metabolic syndrome. Men with elevated baseline heart rates were more likely to experience metabolic syndrome than were those with normal heart rates. This was not true for female patients. The odds ratio $(95 \%$ confidence interval) of developing metabolic syndrome among men in the highest quartile for heart rate was 1.725 (1.282-2.320) compared with those in the lowest quartile. Each increase in the heart rate category led to an approximately 1.2-fold increase in the risk of developing metabolic syndrome for men only, even after adjusting for age and lifestyle. Elevated heart rate is a risk factor for developing metabolic syndrome in men.

Hypertension Research (2009) 32, 801-806; doi:10.1038/hr.2009.109; published online 31 July 2009

Keywords: epidemiology; heart rate; metabolic syndrome; prevention

\section{INTRODUCTION}

Heart rate is easily obtained clinical information, requiring no special instruments or advanced techniques. However, heart rate fluctuates in response to different conditions; hence, it is usually considered to be an unreliable biometric marker for use in epidemiological research. The significance of an increase in heart rate is often underestimated in the clinical setting. Despite these limitations, several studies have reported an association between heart rate and cardiovascular morbidity or mortality ${ }^{1-3}$ and all causes of mortality. ${ }^{1,2,4}$

Individuals with tachycardia often have characteristic features of insulin resistance syndrome, including high blood pressure, obesity, increased blood glucose and insulin levels and an abnormal lipid profile. ${ }^{5-8}$ These features are also the central pathophysiological markers of metabolic syndrome. ${ }^{9}$ The risk factors for metabolic syndrome are highly concordant and the combination of these factors increases the risk of cardiovascular disease. Epidemiological studies indicate that metabolic syndrome affects $\sim 25 \%$ of the population. ${ }^{10,11}$ Metabolic syndrome is also a significant cause of chronic kidney disease $\mathrm{e}^{12}$ and thus end-stage renal disease, cardiovascular disease and premature death. ${ }^{13}$ Metabolic syndrome increases the risk of cardiovascular disease by approximately twofold. ${ }^{14}$ Thus, identifying individuals with metabolic syndrome might allow for early intervention to prevent or mitigate future cardiovascular disease.

The aim of this study was to evaluate whether elevated resting heart rate is predictive of developing metabolic syndrome.

\section{METHODS}

The subjects were participants of a 1-day health evaluation program held by the Okinawa General Health Maintenance Association, which is one of the largest screening centers in Okinawa, Japan. This program provides thorough anthropometric measurements, physical examinations, laboratory tests and electrocardiograms (ECGs) for both individuals and for the health maintenance programs of companies and public organizations. ${ }^{8,15}$

Of the 9914 individuals who participated in the health evaluation program in 1997, 7958 participated in the program at least two more times through 2003. Among these participants, 1677 patients (1315 men and 362 women) treated for heart disease or diagnosed with metabolic syndrome in 1997 were excluded from our study. A total of 6281 participants (3789 men and 2492 women, 20-89 years of age) were included in the present analysis.

The participants were categorized according to heart rate for statistical analysis: Quartile 1 (beats per minute (b.p.m.) $\leqslant 57$ : men, $n=863$; b.p.m. $\leqslant 60$ : women, $n=641)$, Quartile $2(58 \leqslant$ b.p.m. $\leqslant 63$ : men, $n=995 ; 61 \leqslant$ b.p.m. $\leqslant 65$ : women, $n=574$ ), Quartile 3 ( $64 \leqslant$ b.p.m. $\leqslant 69$ : men, $n=1013 ; 66 \leqslant$ b.p.m. $\leqslant 72$ :

${ }^{1}$ Department of Clinical Pharmacology and Therapeutics, Graduate School of Medicine, University of the Ryukyus, Okinawa, Japan; ${ }^{2}$ Dialysis Unit, University Hospital of The Ryukyus, Okinawa, Japan; ${ }^{3}$ Department of Cardiovascular Medicine, Nephrology and Neurology, Faculty of Medicine, University of the Ryukyus, Okinawa, Japan and ${ }^{4}$ Okinawa General Health Maintenance Association, Okinawa, Japan

Correspondence: Dr T Inoue, Department of Clinical Pharmacology and Therapeutics, Graduate School of Medicine, University of the Ryukyus, 207 Uehara Nishihara, Okinawa 903-0125, Japan. 
women, $n=668)$ and Quartile 4 ( $70 \leqslant$ b.p.m.: men, $n=918 ; 73 \leqslant$ b.p.m.: women, $n=609$ ). The prevalence of and risk factors for metabolic syndrome were examined across the four heart rate categories. The participants were followed up for a mean of $47 \pm 16$ months (range: 7-71 months).

This study was conducted in accordance with the principles defined by the Declaration of Helsinki in 1975 and revised in 1993. Data for this study were obtained from the Okinawa General Health Maintenance Association on approval by their ethics committee. The participants' private information was excluded from the original registry database.

\section{Data collection}

Each patient's history of hypertension, diabetes mellitus, hyperlipidemia, current smoking and current alcohol consumption, as well as their physical exercise habits, was determined by self-administered questionnaires and confirmed by a physician's interview. Blood samples were collected after overnight fasting. Trained nurses measured systolic and diastolic blood pressure levels twice using a standard sphygmomanometer after the patient sat quietly for $15 \mathrm{~min}$. The lower of the two blood pressure values was used in the analysis. Body mass index was calculated as body weight $(\mathrm{kg})$ divided by the square of height $\left(\mathrm{m}^{2}\right)$.

\section{Diagnosis of metabolic syndrome}

As waist circumference measurements were not available in this study, we adopted modified versions of the criteria of the National Cholesterol Education Program Adult Treatment Panel III criteria ${ }^{14}$ for the clinical recognition of metabolic syndrome. Participants were diagnosed with metabolic syndrome if they had at least three of the following components: body mass index $\geqslant 25 \mathrm{~kg} \mathrm{~m}^{-2}$ (based on the WHO (World Health Organization) Expert Consultation Committee), ${ }^{16,17}$ elevated triglycerides (TGs $>150 \mathrm{mg}$ per $100 \mathrm{ml}$ ), low high-density lipoprotein cholesterol $(<40 \mathrm{mg}$ per $100 \mathrm{ml}$ in men and $50 \mathrm{mg}$ per $100 \mathrm{ml}$ in women), high blood pressure (systolic blood pressure $\geqslant 130 \mathrm{~mm} \mathrm{Hg}$ and/or diastolic blood pressure $\geqslant 85 \mathrm{~mm} \mathrm{Hg}$ or antihypertensive drug use) and increased plasma glucose (fasting plasma glucose $\geqslant 110 \mathrm{mg}$ per $100 \mathrm{ml}$ or antidiabetic drug use). In addition to the National Cholesterol Education Program Adult Treatment Panel III criterion, we also assessed the effect of heart rate on the risk of developing metabolic syndrome using the International Diabetes Federation definition ${ }^{18}$ and the Definition of the Diagnosis of Metabolic Syndrome in Japan. ${ }^{19}$

\section{Heart rate measurement}

Electrocardiograms were recorded after the participants were in the supine position for $2 \mathrm{~min}$. Heart rate was calculated as the mean RR interval of $5 \mathrm{~s}$ of the ECG recording.

\section{Statistical methods}

We used a one-factor analysis of variance (ANOVA) or a $\chi^{2}$ test to analyze the association of heart rate category with the other values. Two-sided probability values of $<0.05$ were considered to be statistically significant. Multivariate Cox regression analysis was used to evaluate the association of heart rate with developing metabolic syndrome. Hazard ratios and 95\% confidence intervals were computed for incremental changes in categorical variables. We used three models to assess hazard ratios and $95 \%$ confidence intervals for the association between heart rate and developing metabolic syndrome. The first model was a univariate model, whereas model 2 was a multivariate model that calculated the hazard ratio after adjusting for age, smoking, drinking and exercise habits. The third model was a multivariate model that calculated the hazard ratio after adjusting for age, smoking, drinking, exercise habits and the number of elements of metabolic syndrome. All analyses were carried out using the JMP 5.0 software (SAS Institute, Cary, NC, USA). The authors had full access to data and take responsibility for its integrity. All authors have read and agreed to the manuscript as written.

\section{RESULTS}

The heart rate and age distribution of all participants are shown in Figures 1 and 2. The average (s.d.) heart rate and age were 65

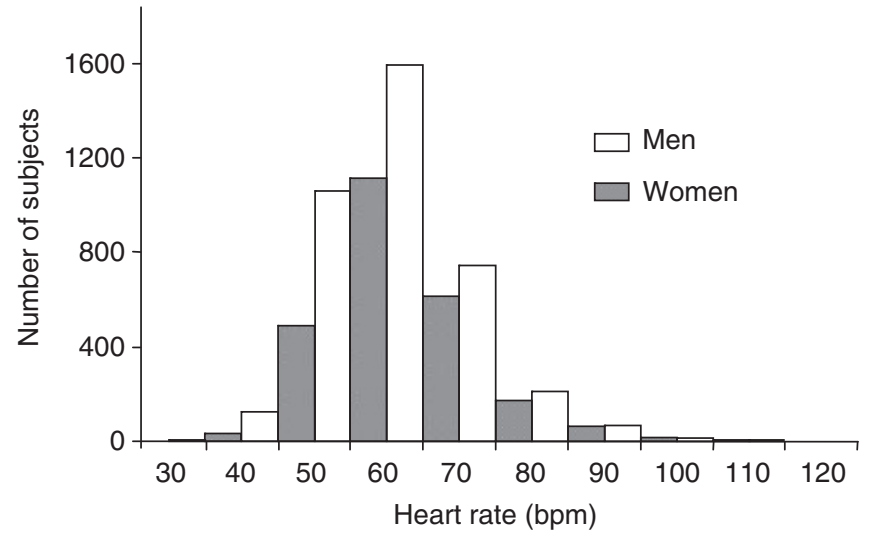

Figure 1 Heart rate distribution in men and women.

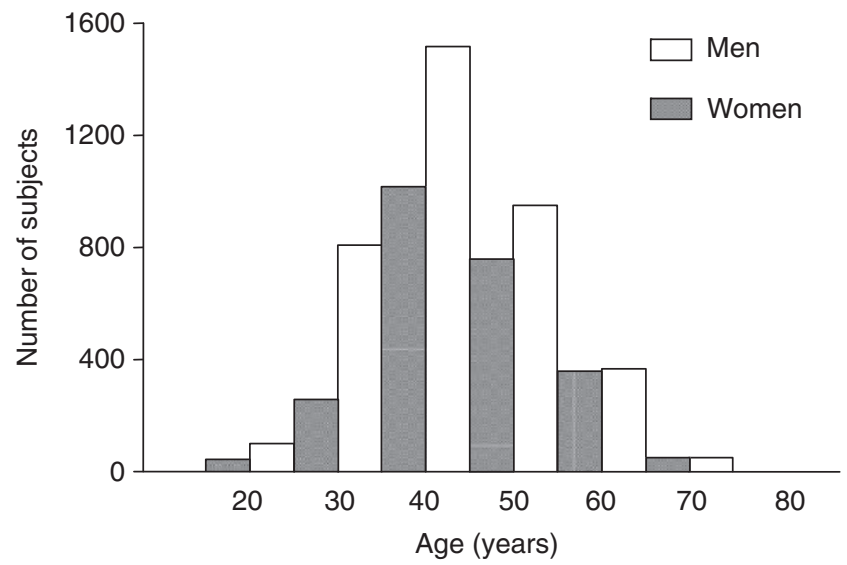

Figure 2 Age distribution of men and women.

(10) b.p.m. and 48.1 (9.9) years, respectively. Baseline characteristics of the participants were categorized across heart rate groups (Table 1). Participants with higher heart rates had significantly higher systolic and diastolic blood pressure and fasting plasma glucose levels than did those with lower heart rates. Male patients with tachycardia were significantly older and had a higher body mass index, serum total cholesterol, TGs and hematocrit and lower high-density lipoprotein cholesterol levels than did those with lower heart rates. This was not true of tachycardic female patients.

Figure 3 shows the association between heart rate and the number of components of metabolic syndrome that was expressed by a particular patient. Participants with more elements of metabolic syndrome had significantly higher heart rates than did those with fewer components of the disease (men, $P<0.001$; women, $P<0.001$; Figure 3).

Of the 6281 enrolled participants, 619 (440 men and 179 women) developed metabolic syndrome over the 5-year follow-up period. Men but not women with higher heart rates developed metabolic syndrome significantly more often than did men in the lower heart rate categories (Figure 4). The odds ratios (95\% confidence interval) for developing metabolic syndrome in men with heart rates in the third and fourth quartiles were $1.41(1.05,1.89)$ and $1.73(1.28,2.32)$, respectively. The cumulative incidence of metabolic syndrome over the 5-year follow-up period is shown in Figure 5. Kaplan-Meier analysis indicates that the incidence of metabolic syndrome was significantly 


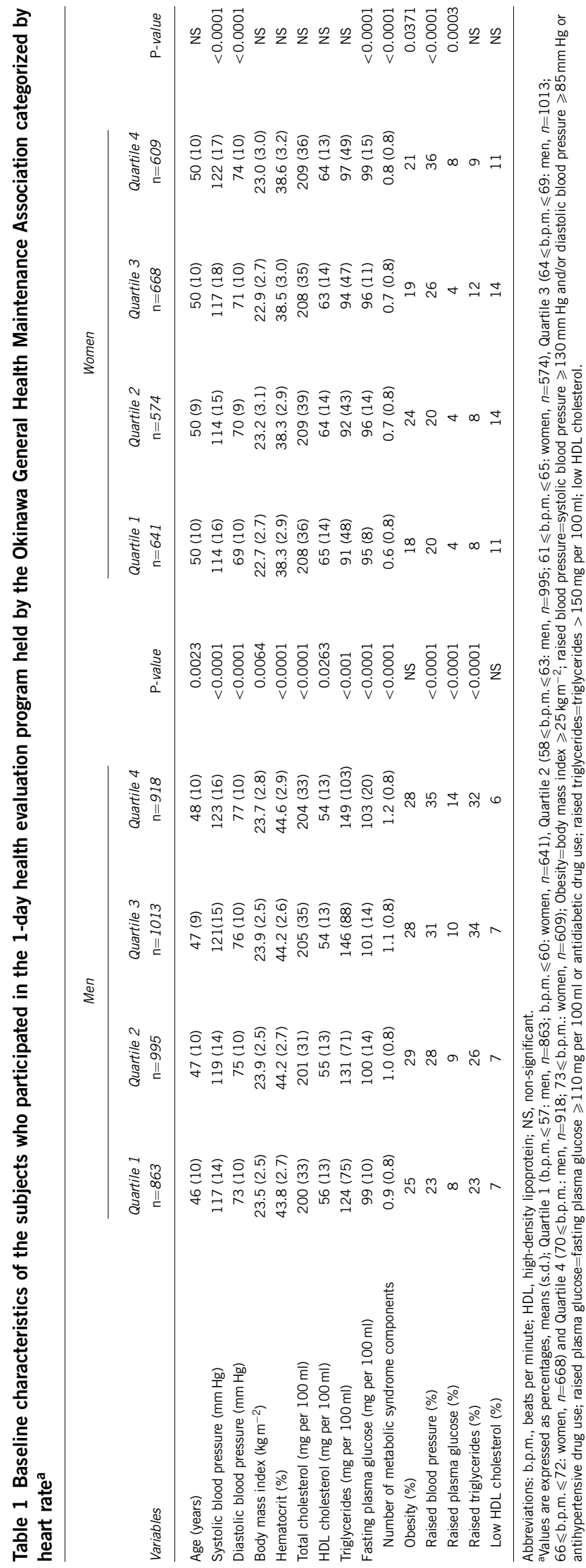

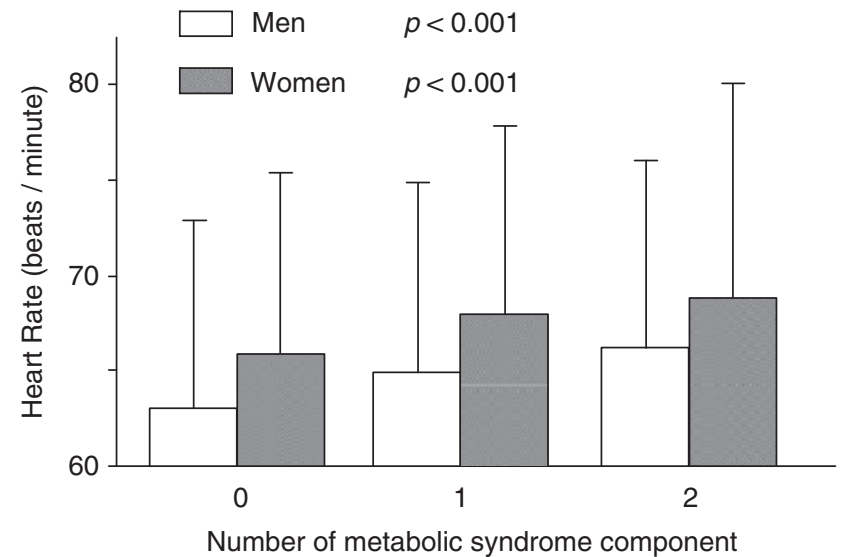

Figure 3 The association between baseline heart rate and the number of components of metabolic syndrome in men and women.

higher in patients with a higher heart rate than in those with a lower heart rate $(P<0.0001)$ for men but not for women.

Results of a Cox regression analysis are shown in Table 2. In men, each categorical increase in heart rate was associated with an approximately 1.2-fold increase in the risk of developing metabolic syndrome in models 1 and 2. However, after we adjusted for age, current smoking, current drinking, exercise habits and the number of elements of metabolic syndrome a patient had (model 3), the risk of developing metabolic syndrome as predicted by tachycardia was blunted.

Meanwhile, heart rate did not predict the development of metabolic syndrome in women. The hazard ratio for developing metabolic syndrome using the International Diabetes Federation definition and Definition of the Diagnosis of Metabolic Syndrome in Japan was also evaluated (Table 2), and no difference was found among the diagnostic criteria. As the ages of our cohort varied widely, we also evaluated the hazard ratio for the development of metabolic syndrome in middle-aged individuals (40-64 years old). The risk of developing metabolic syndrome in middle-aged individuals was nearly identical to that of all individuals considered together.

\section{DISCUSSION}

Numerous studies report that an elevated heart rate correlates with increased blood pressure ${ }^{20,21}$ and is predictive of the development of hypertension. ${ }^{20-22}$ Many patients with tachycardia have the characteristic features of insulin resistance syndrome, namely high blood pressure, obesity, increased blood glucose and insulin and an abnormal lipid profile. ${ }^{7}$ Accordingly, it is likely that tachycardic patients are at a high risk for cardiovascular events ${ }^{8,23}$ and metabolic syndrome.

To date, only one study has indicated that tachycardia predicts the development of metabolic syndrome. ${ }^{24}$ This study followed up middle-aged Japanese men who worked for a single company for 3 years. Subsequent analysis showed that tachycardia was a significant predictor of the development of metabolic syndrome in men with premetabolic syndrome. Our study confirms this result by indicating that tachycardia predicts the onset of metabolic syndrome in men.

However, the correlation between tachycardia and metabolic syndrome is blunted if we adjust for the number of components of metabolic syndrome that a particular patient has at baseline (Table 2). This result suggests that heart rate elevation predicts the development of metabolic syndrome only in individuals with premetabolic 
syndrome. This may be explained by the relatively limited period of follow-up in our study. Four years may not be sufficient time for the low-risk individuals in our present cohort to develop metabolic syndrome. Moreover, the components of metabolic syndrome are closely associated with heart rate, which may explain the loss of significance in the Cox regression analysis when we adjust for these factors (Table 1 and Figure 3).

\section{Mechanisms}

Tachycardia represents an imbalance in central nervous system activity, leading to an increased sympathetic and a decreased parasympathetic tone. ${ }^{6}$ This autonomic dysregulation might explain the connection between heart rate and metabolic syndrome and cardiovascular events through several pathways.

Sympathetic hyperactivity is closely associated with insulin resistance, ${ }^{9,25}$ which has a pivotal role in the pathogenesis of metabolic syndrome. Insulin resistance activates the sympathetic system, increases tubular sodium reabsorption in the kidneys and modulates glucose and lipid metabolism, leading to hypertension, diabetes mellitus and dyslipidemia. ${ }^{26}$ Moreover, insulin resistance results in the activation of proinflammatory factors such as reactive oxygen species, nuclear factor $\kappa \mathrm{B}$ and tumor necrosis factor- $\alpha$ C-reactive protein (CRP), and it causes a suppression of nitric oxide bioavailability. ${ }^{27}$ Tachycardia or autonomic imbalance is also associated with subclinical inflammation represented by an elevated CRP and leukocyte count. ${ }^{28,29}$ Inflammation is believed to have a central role in the pathogenesis and progression of atherosclerosis and is an important risk factor for future cardiovascular events. ${ }^{30}$ In the experimental setting, inflammatory reaction was reduced by sympathectomy. ${ }^{31,32}$ These findings also support the fact that an autonomic imbalance (increased sympathetic activity or reduced parasympathetic activity) could theoretically influence and modulate cardiovascular risk.

Meanwhile, sympathetic hyperactivation is closely associated with abdominal visceral fat independent of total fat mass. ${ }^{33,34}$ Accordingly, metabolic syndrome is considered to be a comprehensive perspective based on interactions between cardiovascular risk factors such as obesity, diabetes, dyslipidemia and chronic inflammation, ${ }^{27}$ and related with sympathetic hyperactivity or tachycardia.
Another possible link between heart rate and metabolic syndrome is leptin, which is an adipocytokine produced by adipose tissue that directly increases sympathetic outflow, ${ }^{35}$ leading to increases in blood
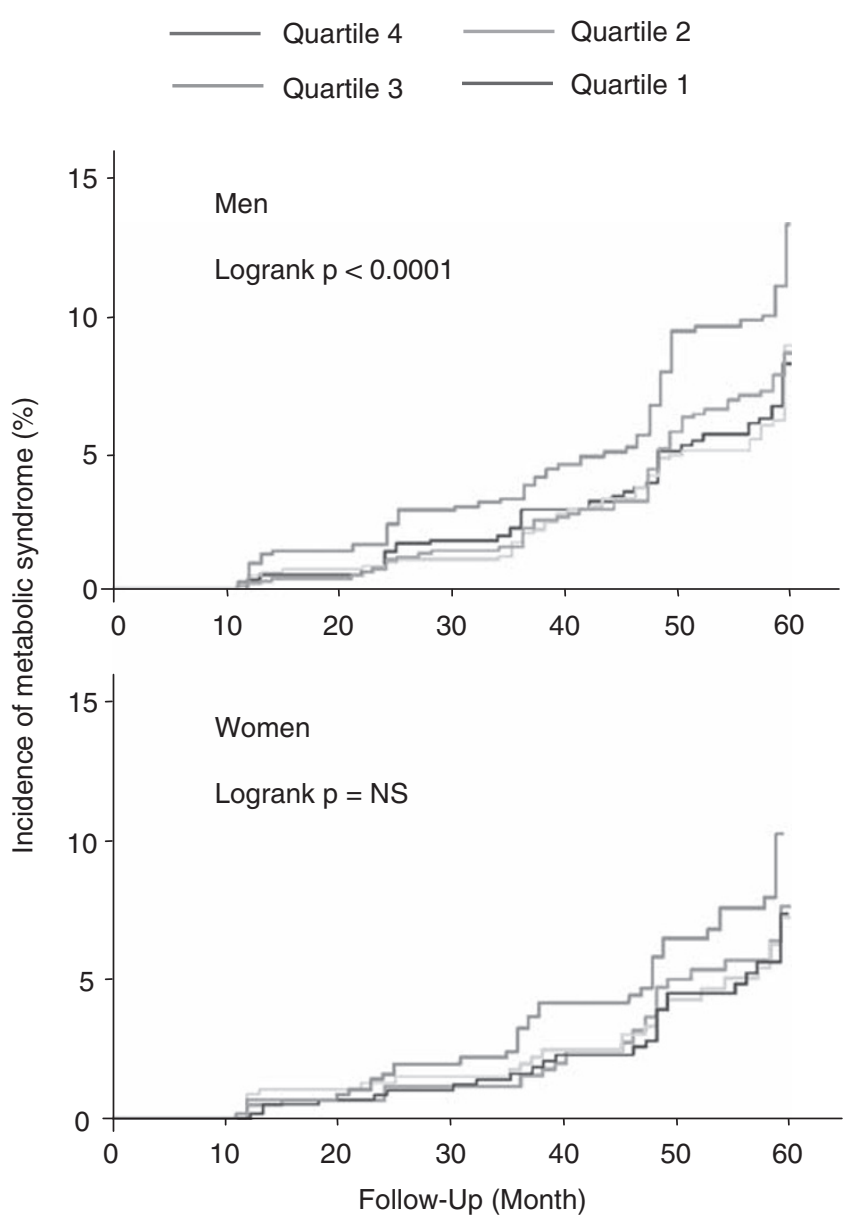

Figure 5 Kaplan-Meier curves showing the incidence of metabolic syndrome according to the baseline heart rate. NS, non-significant. A full color version of this figure is available at the Hypertension Research journal online.

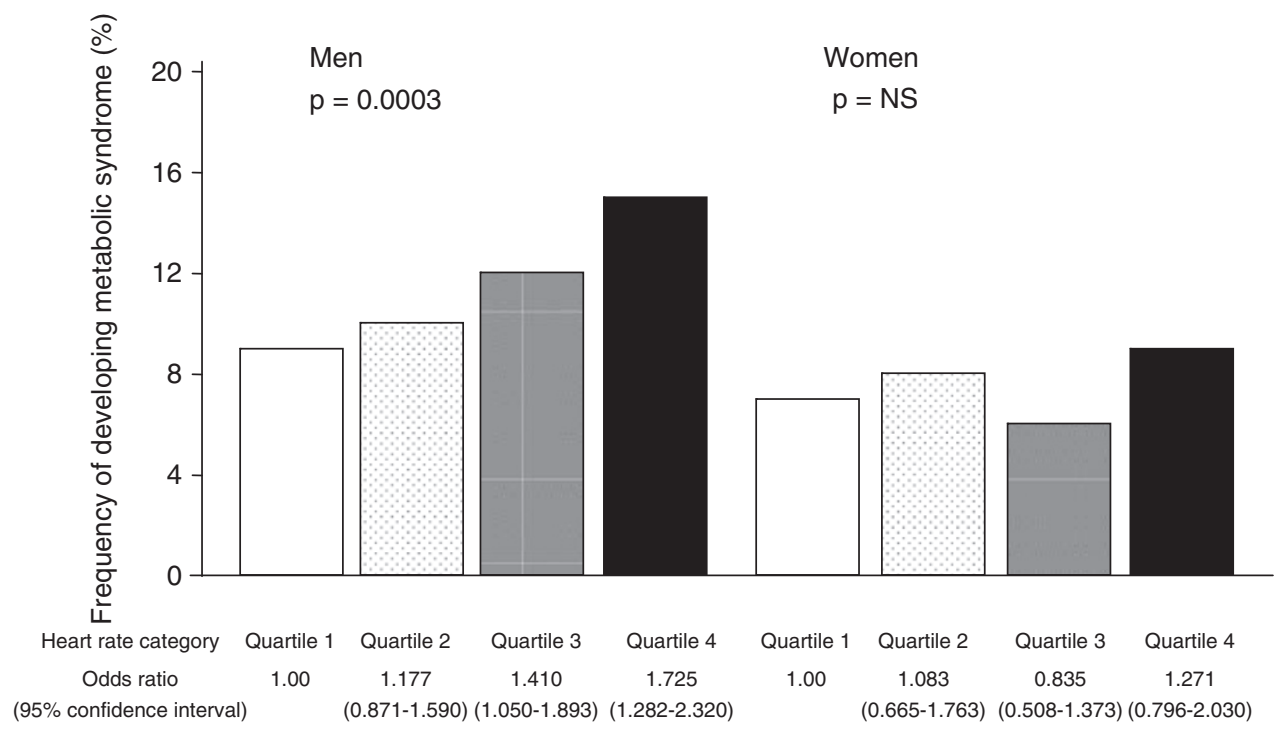

Figure 4 Frequencies and odds ratios for developing metabolic syndrome in each heart rate category over the 5-year follow-up period. NS, non-significant. 
Table 2 Hazard ratio and 95\% confidence interval for developing metabolic syndrome of the subjects who participated in the 1-day health evaluation program held by the Okinawa General Health Maintenance Association

\begin{tabular}{|c|c|c|c|c|c|c|c|c|}
\hline & \multicolumn{4}{|c|}{ Men } & \multicolumn{4}{|c|}{ Women } \\
\hline & \multicolumn{2}{|c|}{ All subjects } & \multicolumn{2}{|c|}{ Middle-aged subjects } & \multicolumn{2}{|c|}{ All subjects } & \multicolumn{2}{|c|}{ Middle aged subjects } \\
\hline \multicolumn{9}{|c|}{ National Cholesterol Education Program Adult Treatment Panel III Criteria } \\
\hline Model $1^{\mathrm{a}}$ & 1.225 & $1.125-1.333$ & 1.244 & $1.129-1.372$ & 1.064 & $0.927-1.221$ & 1.001 & $0.861-1.164$ \\
\hline \multicolumn{9}{|c|}{ International Diabetes Federation Definition } \\
\hline Model $1^{a}$ & 1.212 & $1.084-1.356$ & 1.223 & $1.085-1.378$ & 1.017 & $0.856-1.209$ & 0.951 & $0.783-1.154$ \\
\hline Model $2^{\mathrm{b}}$ & 1.209 & $1.077-1.356$ & 1.218 & $1.077-1.377$ & 1.019 & $0.854-1.215$ & 0.987 & $0.808-1.204$ \\
\hline Model 3c & 1.095 & $0.973-1.232$ & 1.075 & $0.948-1.219$ & 0.974 & $0.819-1.157$ & 0.921 & $0.755-1.124$ \\
\hline
\end{tabular}

Abbreviation: $95 \% \mathrm{Cl}$, 95\% confidence interval.

Hazard ratios and $95 \% \mathrm{Cls}$ were calculated using Cox regression analysis.

aUnivariate model.

aUnivariate model.

${ }^{b}$ Multivariable Cox regression analysis adjusted for age, current smoking, current drinking and habitual exercise.

cMultivariable Cox regression analysis adjusted for age, current smoking, current drinking and habitual exercise and number of component of metabolic syndrome.

pressure and heart rate. ${ }^{36,37}$ Our study confirms previous reports ${ }^{26}$ that sympathetic neural activation and tachycardia are important features of metabolic syndrome. These factors are clearly important in the pathogenesis of cardiovascular disease.

Interestingly, Parkinson's disease may help to explain the link between sympathetic hyperactivity and metabolic syndrome. Parkinson's disease, a natural model of generalized sympathetic denervation, is associated with reduced vascular disease risk factors, such as diabetes, hypertension, hyperglycemia, hypercholesterolemia and elevated TG levels. The reduction in these risk factors is attributed to reduced autonomic activity, suggesting that autonomic hyperactivity may be involved in the pathogenesis of vascular disorders. ${ }^{38}$

A previous study by our group suggested that women have higher heart rates than men in all age groups. ${ }^{8}$ Accordingly, the threshold for tachycardia in women is higher than that for men. ${ }^{7}$ Moreover, the association between heart rate and cardiovascular and/or all causes of mortality is evident in men but not in women. ${ }^{3}$ Gender differences are observed among heart rate, cardiovascular risk factors and mortality, but the reasons for these differences are uncertain.

\section{Clinical implications}

Recently developed biometric tests that measure CRP and urine albumin-creatinine ratio levels $\mathrm{s}^{39,40}$ can predict cardiovascular disease. In the primary prevention of cardiovascular disease, however, simple and cost-effective risk stratification systems with high sensitivities are highly desirable. There have been many attempts to integrate clinical variables into a model for identifying individuals at moderate-to-high cardiovascular risk. ${ }^{14,41-43}$ However, these risk stratification schemes require blood samples and are too complicated for routine clinical use. Measuring heart rate is a routine process that does not require special instruments or advanced techniques, and it would therefore be a simple method to screen for cardiovascular risk and identify patients who may benefit from preventive treatments. By identifying people at risk for developing metabolic syndrome, targeted and cost-effective cardiovascular disease prevention programs can be implemented. Our study suggests that heart rate might be a useful biomarker for patients at risk for developing metabolic syndrome. Tachycardia should be considered a potential predictor of metabolic syndrome, as should cardiovascular events and death.

\section{Limitations}

Several factors limit the scope of our findings. First, the majority of our participants were healthy volunteers who were concerned about their health and thus might not be representative of the general population. Second, the point at which an elevated heart rate becomes hazardous is unclear. Palatini ${ }^{7,44}$ has suggested that $80-85$ b.p.m. is dangerous, whereas other data from Japan indicate that a level higher than 90 b.p.m. is unhealthy. ${ }^{4}$ The recently published Beautiful study, the first prospective randomized controlled trial to address this issue, suggests that 70 b.p.m. is the threshold above which patients are at risk of future cardiovascular events. ${ }^{45}$ However, the patients enrolled in that trial were quite different from our patients. A prospective study is needed to establish the maximum heart rate for primary prevention of cardiovascular events.

In this study, heart rate was calculated from a single ECG recording. As heart rate fluctuates, the average of several ECGs might be a more appropriate measure of heart rate.

\section{CONFLICT OF INTEREST}

The authors declare no conflict of interest.

\section{ACKNOWLEDGEMENTS}

We are grateful to the staff of the Okinawa General Health Maintenance Association and to M Itokazu and K Shiroma for retrieving data. We also thank Ms T Hayashi for her assistance.

1 Kannel WB, Kannel C, Paffenbarger Jr RS, Cupples LA. Heart rate and cardiovascular mortality: the Framingham Study. Am Heart J 1987; 113: 1489-1494. 
2 Gillum RF, Makuc DM, Feldman JJ. Pulse rate, coronary heart disease, and death: the NHANES I Epidemiologic Follow-up Study. Am Heart J 1991; 121: 172-177.

3 Palatini P, Casiglia E, Julius S, Pessina AC. High heart rate: a risk factor for cardiovascular death in elderly men. Arch Intern Med 1999; 159: 585-592.

4 Fujiura Y, Adachi H, Tsuruta M, Jacobs Jr DR, Hirai Y, Imaizumi T. Heart rate and mortality in a Japanese general population: an 18-year follow-up study. J Clin Epidemiol 2001; 54: 495-500.

5 Stern MP, Morales PA, Haffner SM, Valdez RA. Hyperdynamic circulation and the insulin resistance syndrome ('syndrome X'). Hypertension 1992; 20: 802-808.

6 Palatini P, Julius S. Heart rate and the cardiovascular risk. J Hypertens 1997; 15: 3-17.

7 Palatini P, Casiglia E, Pauletto P, Staessen J, Kaciroti N, Julius S. Relationship of tachycardia with high blood pressure and metabolic abnormalities: a study with mixture analysis in three populations. Hypertension 1997; 30: 1267-1273.

8 Inoue T, Oshiro S, Iseki K, Tozawa M, Touma T, Ikemiya Y, Takishita S. High heart rate relates to clustering of cardiovascular risk factors in a screened cohort. Jpn Circ J 2001; 65: 969-973.

9 Hanley AJ, Karter AJ, Festa A, D’Agostino Jr R, Wagenknecht LE, Savage P, Tracy RP, Saad MF, Haffner S. Factor analysis of metabolic syndrome using directly measured insulin sensitivity: The Insulin Resistance Atherosclerosis Study. Diabetes 2002; 51: 2642-2647.

10 McNeill AM, Rosamond WD, Girman CJ, Golden SH, Schmidt MI, East HE, Ballantyne CM, Heiss G. The metabolic syndrome and 11-year risk of incident cardiovascular disease in the atherosclerosis risk in communities study. Diabetes Care 2005; 28 : 385-390.

11 Takeuchi H, Saitoh S, Takagi S, Ohnishi H, Ohhata J, Isobe T, Shimamoto K. Metabolic syndrome and cardiac disease in Japanese men: applicability of the concept of metabolic syndrome defined by the National Cholesterol Education Program-Adult Treatment Panel III to Japanese men-the Tanno and Sobetsu Study. Hypertens Res 2005; 28: 203-208.

12 Tanaka H, Shiohira Y, Uezu Y, Higa A, Iseki K. Metabolic syndrome and chronic kidney disease in Okinawa, Japan. Kidney Int 2006; 69: 369-374.

13 National Kidney Foundation. K/DOQI clinical practice guidelines for chronic kidney disease: evaluation, classification, and stratification. Am J Kidney Dis 2002; 39: S1-S266.

14 Expert Panel on Detection, Evaluation, and Treatment of High Blood Cholesterol in Adults. Executive Summary of The Third Report of The National Cholesterol Education Program (NCEP) Expert Panel on Detection, Evaluation, And Treatment of High Blood Cholesterol In Adults (Adult Treatment Panel III). JAMA 2001; 285: 2486-2497.

15 Tozawa M, Oshiro S, Iseki C, Sesoko S, Higashiuesato Y, Tana T, Ikemiya Y, Iseki K, Fukiyama K. Multiple risk factor clustering of hypertension in a screened cohort. J Hypertens 2000; 18: 1379-1385.

16 WHO. Physical status: the use and interpretation of anthropometry, in: Report of a WHO Expert Consultation. WHO Technical Report Series Number 854. World Health Organization: Geneva, 1995

17 WHO Expert Consultation. Appropriate body-mass index for Asian populations and its implications for policy and intervention strategies. Lancet 2004; 363: 157-163.

18 Alberti KG, Zimmet P, Shaw J. Metabolic syndrome - a new world-wide definition. A Consensus Statement from the International Diabetes Federation. Diabet Med 2006; 23: 469-480.

19 The Committee on the Diagnosis of Metabolic Syndrome: the definition and diagnostic criteria of Metabolic Syndrome. Nippon Naika Gakkai Zasshi 2005; 94: 188-203 (in Japanese).

20 Levy RL, White PD, Stround WD, Hillman CC. Transient tachycardia: prognostic significance alone and in association with transient hypertension. JAMA 1945; 129: 585-588.

21 Julius S. Transition from high cardiac output to elevated vascular resistance in hypertension. Am Heart J 1988; 116: 600-606.

22 Inoue T, Iseki K, Iseki C, Kinjo K, Ohya Y, Takishita S. Higher heart rate predicts the risk of developing hypertension in a normotensive screened cohort. Circ J 2007; 71: 1755-1760.

23 Inoue T, Iseki K, Iseki C, Ohya Y, Kinjo K, Takishita S. Association between heart rate and multiple risk factor syndrome: cross-sectional analysis of a screened cohort in Okinawa, Japan. Circ J 2008; 72: 454-457.
24 Tomiyama H, Yamada J, Koji Y, Yambe M, Motobe K, Shiina K, Yamamoto Y, Yamashina A. Heart rate elevation precedes the development of metabolic syndrome in Japanese men: a prospective study. Hypertens Res 2007; 30: 417-426.

25 Vollenweider P, Randin D, Tappy L, Jequier E, Nicod P, Scherrer U. Impaired insulininduced sympathetic neural activation and vasodilation in skeletal muscle in obese humans. J Clin Invest 1994; 93: 2365-2371.

26 Reaven G. Metabolic syndrome: pathophysiology and implications for management of cardiovascular disease. Circulation 2002; 106: 286-288.

27 Dandona P, Aljada A, Chaudhuri A, Mohanty P, Garg R. Metabolic syndrome: a comprehensive perspective based on interactions between obesity, diabetes, and inflammation. Circulation 2005; 111: 1448-1454.

28 Sajadieh A, Nielsen OW, Rasmussen V, Hein HO, Abedini S, Hansen JF. Increased heart rate and reduced heart-rate variability are associated with subclinical inflammation in middle-aged and elderly subjects with no apparent heart disease. Eur Heart J 2004; 25: 363-370.

29 Janszky I, Ericson M, Lekander M, Blom M, Buhlin K, Georgiades A, Ahnve S. Inflammatory markers and heart rate variability in women with coronary heart disease. J Intern Med 2004; 256: 421-428.

30 Willerson JT, Ridker PM. Inflammation as a cardiovascular risk factor. Circulation 2004; 109: II2-I10.

31 Madden KS, Felten SY, Felten DL, Hardy CA, Livnat S. Sympathetic nervous system modulation of the immune system. II. Induction of lymphocyte proliferation and migration in vivo by chemical sympathectomy. J Neuroimmunol 1994; 49: 67-75.

32 Juttler E, Tarabin V, Schwaninger M. Interleukin-6 (IL-6): a possible neuromodulator induced by neuronal activity. Neuroscientist 2002; 8: 268-275.

33 Jones PP, Davy KP, Alexander S, Seals DR. Age-related increase in muscle sympathetic nerve activity is associated with abdominal adiposity. Am J Physiol 1997; 272: E976-E980.

34 Alvarez GE, Beske SD, Ballard TP, Davy KP. Sympathetic neural activation in visceral obesity. Circulation 2002; 106: 2533-2536.

35 Haynes WG, Morgan DA, Walsh SA, Mark AL, Sivitz WI. Receptor-mediated regional sympathetic nerve activation by leptin. J Clin Invest 1997; 100: 270-278.

36 Dunbar JC, Hu Y, Lu H. Intracerebroventricular leptin increases lumbar and renal sympathetic nerve activity and blood pressure in normal rats. Diabetes 1997; 46: 2040-2043.

37 Shek EW, Brands MW, Hall JE. Chronic leptin infusion increases arterial pressure. Hypertension 1998; 31: 409-414.

38 Scigliano G, Musicco M, Soliveri P, Piccolo I, Ronchetti G, Girotti F. Reduced risk factors for vascular disorders in Parkinson disease patients: a case-control study. Stroke 2006; 37: 1184-1188.

39 Kuusisto J, Mykkanen L, Pyorala K, Laakso M. Hyperinsulinemic microalbuminuria. A new risk indicator for coronary heart disease. Circulation 1995; 91: 831-837.

40 Ridker PM, Buring JE, Shih J, Matias M, Hennekens $\mathrm{CH}$. Prospective study of C-reactive protein and the risk of future cardiovascular events among apparently healthy women. Circulation 1998; 98: 731-733.

41 Wilson PW, D'Agostino RB, Levy D, Belanger AM, Silbershatz H, Kannel WB. Prediction of coronary heart disease using risk factor categories. Circulation 1998; 97: 1837-1847.

42 Wood D, De Backer G, Faergeman O, Graham I, Mancia G, Pyorala K. Prevention of coronary heart disease in clinical practice: recommendations of the Second Joint Task Force of European and other Societies on Coronary Prevention. Atherosclerosis 1998; 140: 199-270.

43 Conroy RM, Pyorala K, Fitzgerald AP, Sans S, Menotti A, De Backer G, De Bacquer D, Ducimetiere P, Jousilahti P, Keil U, Njolstad I, Oganov RG, Thomsen T, Tunstall-Pedoe H, Tverdal A, Wedel H, Whincup P, Wilhelmsen L, Graham IM. Estimation of ten-year risk of fatal cardiovascular disease in Europe: the SCORE project. Eur Heart J 2003; 24: 987-1003.

44 Palatini P. Need for a revision of the normal limits of resting heart rate. Hypertension 1999; 33: 622-625.

45 Fox K, Ford I, Steg PG, Tendera M, Ferrari R. Ivabradine for patients with stable coronary artery disease and left-ventricular systolic dysfunction (BEAUTIFUL): a randomised, double-blind, placebo-controlled trial. Lancet 2008; 372: 807-816. 